\title{
Can short-term residential care for stroke rehabilitation help to reduce the institutionalization of stroke survivors?
}

This article was published in the following Dove Press journal:

Clinical Interventions in Aging

12 February 2014

Number of times this article has been viewed

\section{Pui Hing Chau' \\ Maria WS Tang ${ }^{2}$ \\ Fannie Yeung ${ }^{2}$ \\ Tsz Wai Chan' \\ Joanna OY Cheng' \\ Jean Woo}

'School of Nursing, University of Hong Kong, Hong Kong, Special Administrative Region of the People's Republic of China; ${ }^{2}$ Department of Medicine and Therapeutics, Chinese University of Hong Kong, Hong Kong, Special Administrative Region of the People's Republic of China
Correspondence: Pui Hing Chau School of Nursing, University of Hong Kong, 4/F, William MW Mong Block, 2I Sassoon Road, Pokfulam, Hong Kong, Special Administrative Region of the People's Republic of China

Tel +85228192626

Fax +852 28726079

Email phchau@graduate.hku.hk
Background: Stroke survivors may not be receiving optimal rehabilitation as a result of a shortage of hospital resources, and many of them are institutionalized. A rehabilitation program provided in a short-term residential care setting may help to fill the service gap.

Objectives: The primary objectives of this study were, first, to examine whether there were significant differences in terms of rehabilitation outcomes at 1 year after admission to the rehabilitation program (defined as baseline) between those using short-term residential care (intervention group) and those using usual geriatric day hospital care (control group), and, second, to investigate whether lower 1-year institutionalization rates were observed in the intervention group than in the control group.

Participants: 155 stroke survivors who completed at least the first follow-up at 4 months after baseline.

Intervention: The intervention group was stroke survivors using self-financed short-term residential care for stroke rehabilitation. The control group was stroke survivors using the usual care at a public geriatric day hospital.

Measurements: Assessments were conducted by trained research assistants using structured questionnaires at baseline, 4 months, and 1 year after baseline. The primary outcome measures included Modified Barthel Index score, Mini-Mental Status Examination score, and the institutionalization rate.

Results: Cognitive status (as measured by Mini-Mental Status Examination score) of patients in both groups could be maintained from 4 months to 1 year, whereas functional status (as measured by Modified Barthel Index score) of the patients could be further improved after 4 months up to 1 year. Meanwhile, insignificant between-group difference in rehabilitation outcomes was observed. The intervention participants had a significantly lower 1-year institutionalization rate $(15.8 \%)$ than the control group (25.8\%).

Conclusion: Short-term residential care for stroke rehabilitation promoted improvements in rehabilitation outcomes comparable with, if not better than, the usual care at geriatric day hospital. Furthermore, it had a significantly lower 1-year institutionalization rate. This type of service could be promoted to prevent institutionalization.

Keywords: stroke, institutionalization, rehabilitation, residential care, day hospital

\section{Introduction}

Stroke is a major contributor to functional and cognitive impairments, which are risk factors to institutionalization. ${ }^{1-5}$ Institutionalization after stroke is common around the world. In Australia, 5\% of stroke survivors are institutionalized by the first year after stroke. ${ }^{4}$ In Europe, the institutionalization rates among stroke survivors are 26\% (at discharge) in Italy and 19\% (at 5 years after stroke) in the United Kingdom. ${ }^{6,7}$ 
In the United States, $35 \%$ of female stroke survivors and $10 \%$ of male stroke survivors are institutionalized at 3-6 months poststroke. ${ }^{8}$ In Hong Kong, the proportion of stroke survivors who are institutionalized is as high as $37 \%$, excluding those already living in residential care before stroke onset. ${ }^{9}$ Meanwhile, the decision for institutionalization not only depends on the condition of the patients but also their family caregivers play an active role. Caregivers with greater caregiver burden, which is the case for caregivers to stroke patients, are more likely to favor institutionalization as the care option. $^{10,11}$

In view of the cost constraints in respect of inpatient rehabilitation services, rehabilitation programs for stroke survivors may not be optimal to enable them to return to community living, predisposing to premature institutionalization on discharge from hospital. Despite the best rehabilitation period spanning the first 6 months after stroke, ${ }^{12}$ inpatient rehabilitation duration seldom meets such a target. Duration of inpatient stays is kept to a minimal. , $^{9,13,14}$ Stroke patients treated at private hospitals (ie, non-publicly funded hospitals) also face the problem of shorter length of stay related to the high charges. Furthermore, rehabilitation care in private hospitals is very limited and unreasonably expensive, if there is any. To receive outpatient rehabilitation, exhaustive traveling is unavoidable unless rehabilitation programs are provided at a residential care or outreach setting. However, rehabilitation in traditional nursing homes (in contrast to skilled nursing homes) is insufficient, and outreach rehabilitation is limited by the size of the physical environment and a lack of outreach rehabilitation service providers. ${ }^{15-17}$ Stroke patients, those treated in both public and private settings, are not getting the optimal rehabilitation care they need, and it costs a lot.

The high institutionalization rate among stroke patients might lead to the large proportion of the institutionalized population. Therefore, it is important to prevent institutionalization of these survivors by provision of adequate rehabilitation services. Transitional care in the form of a short-term residential care setting may fill the service gap. Although there are different forms of transitional care, transitional care in this setting is seldom discussed. ${ }^{18}$

In 2009, a nongovernmental organization in Hong Kong operated a self-financed short-term residential care service with onsite rehabilitation for older stroke patients. The nongovernmental organization aimed to provide more rehabilitation options for stroke patients who were able to afford user-pay/copayment services. Moreover, the service aimed to facilitate the stroke patients being able to return to their own home after they completed the rehabilitation program in approximately 4 months. We conducted a quasi-experimental study to evaluate the effectiveness of this new service option compared with the usual care at a geriatric day hospital (GDH) that provided outpatient rehabilitation services for older patients. In the interim analysis, we found that both the intervention and control participants showed significant improvement in functional and cognitive status at 4 months after the start of the program, and that the two groups could achieve similar improvements in the outcomes. ${ }^{19}$ Given that the rehabilitation program is usually terminated after 4 months, there is a need to assess the between-group differences at 1 year after the start of the program and whether the improvement in outcomes can be maintained 1 year after the start of the program.

The primary objectives of this study were 1) to examine whether there were significant between-group differences in terms of rehabilitation outcomes at 1 year after the start of the rehabilitation program, and 2) to investigate whether the intervention group had lower institutionalization rates than the control group. The secondary objective was to explore whether the improvement in the rehabilitation outcomes was maintained up to 1 year after the start of the rehabilitation program. It was hypothesized that the improvements in functional and cognitive status were maintained for 1 year without between-group differences, and the institutionalization rate was lower in the intervention group.

\section{Methods \\ Data collection}

During June 2009 to April 2013, a quasi-experimental study on the effectiveness of a new service option of short-term residential care for older stroke patients was conducted. Users of the new service option and their caregivers were recruited for the intervention group, and users of the usual public GDH option and their caregivers were recruited for the control group. Both the services provided approximately 12 hours of physiotherapy and occupational therapy a week. The new service provided such therapy 6 days a week, but the usual care option compressed all therapy hours into 2 days. The new service had the following additional features to the usual care: 1) round-the-clock nursing care and residential care, 2) a home-like environment, and 3) more advanced rehabilitation equipment, like computer games.

The potential participants in the intervention group and the control group were those who opted to use the new service and the usual service, respectively. The participants were screened for eligibility and recruited at admission to the corresponding services, which was defined as the baseline 
of this study. Follow-up assessments were conducted at 4 months and 1 year after admission to the rehabilitation services (defined as 4-month follow-up and 1-year follow-up, respectively). The inclusion criteria were Chinese stroke patients at hospital discharge who were 1) free of communicable disease, 2) emotionally calm, 3) able to understand rehabilitation instructions, 4) within 6 months after stroke, and 5) in a community-dwelling population before stroke onset. Criteria 2) and 3) were assessed according to the service providers' opinion. No objective measures were used. Community dwelling status is reflected by the residential addresses. In addition, control participants were matched to the intervention group for age, sex, and functional status as far as possible. The exclusion criteria were patients who experienced 1) stroke recurrence within the study period and 2) readmission to hospital around follow-up time for over 1 month. Details of the treatments and subject recruitments are presented in Chau et al. ${ }^{19}$ At baseline, 60 intervention participants and 128 control participants were recruited to this study, with a response rate of $90.8 \%$. At 4-month followup, 50 intervention participants and 105 control participants were interviewed. The participants were interviewed again at 1-year follow-up. This paper utilized all data available at 1 year. To minimize attrition, the stroke survivors were contacted through both residential telephones and mobile phones. If they could not be reached, their caregivers would be contacted to locate the stroke survivors. Informed consent was obtained from the participants, and the study was approved by the ethical committee of the Chinese University of Hong Kong, Hong Kong, Special Administrative Region of the People's Republic of China.

\section{Instruments}

Interviews were conducted by trained research assistants using structured questionnaires. Functional status of the stroke patients was assessed by the Chinese version of the Modified Barthel Index (MBI) (range 0-100), and a higher score indicated a higher functional status. ${ }^{20,21}$ Cognitive status of the stroke patients was assessed by the Chinese version of the Mini-Mental Status Examination (MMSE) (range 0-30), and a higher score indicated a higher cognitive status. ${ }^{22}$ Depressive symptoms of the stroke patients were assessed by the Chinese version of the Geriatric Depression Scale (GDS) (range 0-15), and a higher score indicated more depressive symptoms. ${ }^{23}$ State of self-esteem of the stroke patients was assessed by the Chinese version of the State Self-Esteem Scale (SSES) (range 20-100), and a higher score indicated a higher self-worth. ${ }^{24-26}$ Psychosocial outcomes were not collected from cognitively impaired participants (MMSE score $<19$ ). Caregiver burden was assessed by the Chinese version of the Zarit Burden Interview (ZBI) (range 0-88), and a higher score indicated a higher burden. ${ }^{27,28}$

Institutionalization was defined as a long stay in residential care facilities 1 year after baseline. "Long stay" is defined as living in the institutions without any intention to return to community-dwelling living. Respite care that had a planned and limited length of stay was not classified as institutionalization. The place of residence of the stroke patients (living at their own home or a residential care home) at 1 year after baseline was indicated by the residential address of the patients. If intervention participants were still utilizing stroke rehabilitation in a residential care setting by that time, they were considered as being institutionalized.

The primary outcome measures were MBI and MMSE scores and the institutionalization rate, and the secondary outcome measures were GDS, SSES, and ZBI scores.

\section{Statistical analysis}

To examine whether the improvement in outcome measures in the two follow-ups differed between the two groups, linear mixed-effects models were adopted. These models could take into account the correlation resulting from the repeated measures and included the dropout cases at 1 year in the model fitting. However, dropout cases at 4 months were excluded from this analysis. Participants who did not complete the rehabilitation program were still analyzed according to their initial groupings (intention to treat). Separate models were fitted for each outcome measure separately. For outcome measures of the stroke patients (ie, MBI, MMSE, SSES, and GDS), group (intervention and control), time of measurement (4 months and 1 year), interaction between group and time, age and sex of the stroke patients, stroke type, household income, and the corresponding outcome measure at baseline were used as covariates. Insignificant interaction would be removed for further analysis of the time and group effects. For outcome measure of the caregivers (ie, ZBI), age and sex of the caregivers and baseline values of MBI and MMSE of the stroke patients were also included as covariates. These settings could account for the baseline differences between the two groups and address the issue of regression to the mean.

Multiple logistic regression was used to examine whether the institutionalization rates at 1 year were different between the intervention group and the control group. The age and sex of the stroke patients and their caregivers, stroke type, household income, as well as the baseline functional status 
(MBI score $\leq 51$ [the median] versus MBI score $>51$ ) and cognitive status (MMSE score $\leq 18$ [cognitively impaired] versus MMSE score >18) were included as control variables. Although usage of a domestic helper is a possible predictor of institutionalization, ${ }^{5}$ this variable was not included as a control variable because almost all the institutionalized control participants were institutionalized immediately after their inpatient discharge. Therefore, the usage of a domestic helper reported might not be a preceding factor of institutionalization. Rather, non-usage could be a result from institutionalization. Meanwhile, caregiver burden (ie, ZBI score) was not included as a control variable because a previous study showed that after controlling for the functional status of the older people, the caregiver burden became an insignificant factor to institutionalization. ${ }^{5}$ Odds ratios (ORs) and the corresponding 95\% confidence intervals (CIs) were derived from the model.

Although age and sex of the stroke patients were matched as far as possible in subject recruitment, these variables were controlled in the analyses, as these were well-known predictors to the outcomes. SPSS version 20.0 (IBM Corporation, Armonk, NY, USA) was used for the analysis, and a significance level of 5\% was adopted. Correction for multiple comparisons (for MBI, MMSE, SSES, GDS, and ZBI) was not applied, as the more stringent significance level adopted would favor the acceptance of noninferiority of the intervention group that was to be demonstrated. Table S1 shows the summary of the analysis plan.

\section{Results}

\section{Overview}

At 1-year follow-up, 38 intervention participants and 89 control participants completed the study. Overall attrition rate (compared with baseline) was $32.4 \%$. There were no significant differences in baseline characteristics and outcome measures between dropout participants and those who completed the 1-year follow-up. Figure 1 shows the study flow.
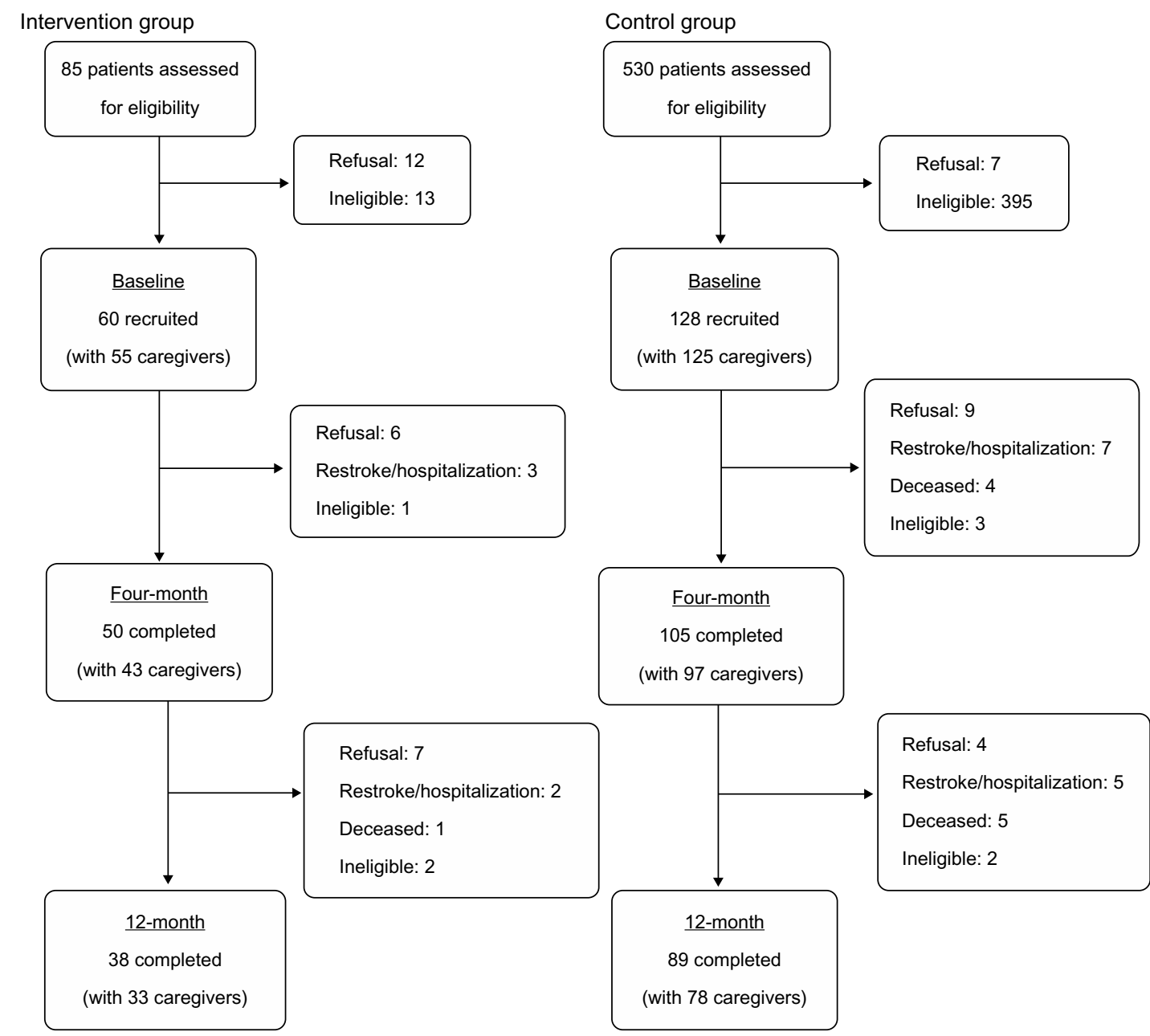

Figure I Study flow. 


\section{Rehabilitation outcomes}

The analyses of rehabilitation outcomes were based on the 50 intervention participants and 105 control participants who completed 4-month follow-up, as dropout at 1 year could be accounted for by the statistical model. Table 1 shows the characteristics of the participants included in this analysis. The stroke patients in the intervention group had a mean age of 71.5 years (standard deviation [SD]: 10.5), and those in the control group had a mean age of 72.3 years (SD: 10.2). About $48.0 \%$ of intervention participants and $59.0 \%$ of control participants were male. Participants of the two groups had insignificant difference in most baseline characteristics, except household income, type of stroke, and baseline MBI and GDS scores. As these variables were included as control variables in the statistical models, the between-group differences (if any) would not be an artifact of failure to include these possible confounders.

Table 2 shows the improvements in outcome measures at 4 months and 1 year compared with baseline. The mean changes in MBI in 1 year compared with baseline were 17.360 (95\% CI: 12.624-22.095) for the control group and 23.158 (95\% CI: 17.939-28.377) for the intervention group, whereas the mean changes in MMSE were 0.988 (95\% CI: -0.095 to 2.071 ) and 0.639 (95\% CI: -0.591 to 1.869), respectively, for the two groups in the same period. From the linear mixed-effects models, the interaction terms between time and group were all insignificant for the five outcome measures ( $P$-value ranged from 0.315 to $0.855)$, implying that the between-group difference, if any, was constant across time. The insignificant interaction terms were then removed but retaining all other control variables.

Based on the linear mixed-effects models, all betweengroup differences in the five rehabilitation outcomes were statistically insignificant ( $P$-value ranged from 0.267 to 0.935$)$, implying that the intervention group achieved rehabilitation outcomes comparable with the control group (Table 2). Furthermore, it was unlikely that the small sample size failed to detect worse outcomes in the intervention group because the point estimates of the between-group differences showed that the intervention group appeared to have more favorable point estimates of outcome measures after rehabilitation than the control group. For example, the intervention group had higher MBI score by 2.282 units (95\% CI: -4.410 to 8.974 ), higher SSES score by 2.523 units (95\% CI: -1.970 to 7.016 ), and lower ZBI score by 2.236 units (95\% CI: -2.674 to 7.146 ) than the control group.

Both groups had an increased MBI score of 4.072 (95\% CI: 1.867-6.276) at 1 year compared with 4 months,
Table I Baseline characteristics of the participants who completed 4-month follow-up

\begin{tabular}{|c|c|c|c|}
\hline & $\begin{array}{l}\text { Intervention } \\
\text { group } \\
\end{array}$ & $\begin{array}{l}\text { Control } \\
\text { group } \\
\end{array}$ & $\begin{array}{l}P \text {-value for } \\
\text { baseline } \\
\text { difference }\end{array}$ \\
\hline \multirow{2}{*}{\multicolumn{4}{|c|}{ Patient }} \\
\hline & & & \\
\hline $\mathrm{N}$ & 50 & 105 & \\
\hline Age, year (mean $\pm S D$ ) & $71.5 \pm 10.5$ & $72.3 \pm 10.2$ & 0.662 \\
\hline Sex & & & 0.196 \\
\hline Male & $24,48.0 \%$ & $62,59.0 \%$ & \\
\hline Female & $26,52.0 \%$ & $43,41.0 \%$ & \\
\hline Monthly household & & & $0.013^{b}$ \\
\hline \multicolumn{4}{|l|}{ income, HK\$a } \\
\hline$<15,000$ & $25,50.0 \%$ & $79,75.2 \%$ & \\
\hline$\geq 15,000$ & $20,40.0 \%$ & $25,23.8 \%$ & \\
\hline Missing & $5,10.0 \%$ & I, $1.0 \%$ & \\
\hline Marital status & & & 0.986 \\
\hline Never married & I, $2.0 \%$ & $2,1.9 \%$ & \\
\hline Now married & $33,66.0 \%$ & $68,64.8 \%$ & \\
\hline $\begin{array}{l}\text { Separated/divorced/ } \\
\text { widowed }\end{array}$ & $16,32.0 \%$ & $35,33.3 \%$ & \\
\hline First ever stroke & & & 0.666 \\
\hline Yes & $40,80.0 \%$ & $87,82.9 \%$ & \\
\hline No & $10,20.0 \%$ & $18,17.1 \%$ & \\
\hline Type of stroke & & & $0.016^{\mathrm{b}}$ \\
\hline Ischemic & $32,64.0 \%$ & $85,81.0 \%$ & \\
\hline Hemorrhagic & $18,36.0 \%$ & $19,18.1 \%$ & \\
\hline Missing & & $1,1.0 \%$ & \\
\hline $\begin{array}{l}\text { Time from stroke } \\
\text { to rehabilitation, } \\
\text { month (mean } \pm S D \text { ) }\end{array}$ & $2.0 \pm 1.1$ & $1.7 \pm 0.9$ & 0.113 \\
\hline $\begin{array}{l}\text { Duration of rehabilitation, } \\
\text { month }\end{array}$ & & & 0.125 \\
\hline$\leq \mathrm{I}$ month & $\mathrm{I}, 2.0 \%$ & $12,11.4 \%$ & \\
\hline I.I-4 months & $30,60.0 \%$ & $53,50.5 \%$ & \\
\hline$>4$ months & $19,38.0 \%$ & $40,38.1 \%$ & \\
\hline $\mathrm{MBI}($ mean $\pm \mathrm{SD})$ & $40.9 \pm 23.3$ & $51.4 \pm 20.4$ & $0.005^{b}$ \\
\hline MMSE (mean \pm SD) & $20.5 \pm 7.8$ & $19.9 \pm 6.5$ & 0.669 \\
\hline GDS (mean \pm SD) & $8.3 \pm 3.3$ & $6.5 \pm 3.4$ & $0.015^{b}$ \\
\hline SSES (mean \pm SD) & $73.1 \pm 10.6$ & $70.5 \pm 12.7$ & 0.328 \\
\hline \multicolumn{4}{|l|}{ Caregiver } \\
\hline $\mathrm{N}$ & 43 & 97 & \\
\hline Age, year (mean $\pm S D)$ & $55.3 \pm 12.0$ & $54.5 \pm 11.3$ & 0.700 \\
\hline Sex & & & 0.200 \\
\hline Male & $8,18.6 \%$ & $28,28.9 \%$ & \\
\hline Female & $35,81.4 \%$ & $69,71.1 \%$ & \\
\hline Living with patients & & & 0.964 \\
\hline Yes & $25,58.1 \%$ & $56,57.7 \%$ & \\
\hline No & $18,41.9 \%$ & $41,42.3 \%$ & \\
\hline Relationship with patient & & & 0.955 \\
\hline Spouse & $19,44.2 \%$ & $44,45.4 \%$ & \\
\hline Children/children-in-law & $23,53.5 \%$ & $50,51.5 \%$ & \\
\hline Others & $\mathrm{I}, 2.3 \%$ & $3,3.1 \%$ & \\
\hline Domestic helper & & & 0.268 \\
\hline Yes & II, $25.6 \%$ & $34,35.1 \%$ & \\
\hline No & $32,74.4 \%$ & $63,64.9 \%$ & \\
\hline $\mathrm{ZBI}(\operatorname{mean} \pm \mathrm{SD})$ & $30.8 \pm 15.5$ & $35.7 \pm 15.8$ & 0.095 \\
\hline
\end{tabular}

Notes: ${ }^{a} \mathrm{HK} \$ 7.8=$ US $\$$; ${ }^{b}$ significant baseline difference at $5 \%$ level of significance.

Abbreviations: GDS, Geriatric Depression Scale; MBI, Modified Barthel Index; MMSE, Mini-Mental Status Examination; N, sample size; n, count; SD, standard deviation; SSES, State Self-Esteem Scale; ZBI, Zarit Burden Interview. 
Table 2 Changes in the outcome measures at 4 months and 12 months compared with baseline

\begin{tabular}{|c|c|c|c|c|c|c|}
\hline \multirow{4}{*}{$\begin{array}{l}\text { Outcome } \\
\text { measures }\end{array}$} & \multicolumn{4}{|c|}{ Mean changes as compared with baseline $(95 \% \mathrm{Cl})$} & \multirow{3}{*}{\multicolumn{2}{|c|}{$\begin{array}{l}\text { Adjusted between-group } \\
\text { difference (control group } \\
\text { as reference) }^{\mathrm{a}}\end{array}$}} \\
\hline & \multicolumn{2}{|c|}{ Intervention group } & \multicolumn{2}{|l|}{ Control group } & & \\
\hline & \multirow{2}{*}{4 months } & \multirow{2}{*}{12 months } & \multirow{2}{*}{4 months } & \multirow{2}{*}{12 months } & & \\
\hline & & & & & Estimate $(95 \% \mathrm{Cl})$ & $P$-value \\
\hline MBI & $15.3(10.8-19.8)$ & $23.2(17.9-28.4)$ & | $3.3(9.7-16.8)$ & $17.4(12.6-22.1)$ & $2.3(-4.4$ to 9.0$)$ & $0.50 I^{b}$ \\
\hline MMSE & $1.3(0.4-2.1)$ & $0.6(-0.6$ to 1.9$)$ & I.I (0.4-1.9) & $1.0(-0.1$ to 2.1$)$ & $-0.1(-1.3$ to 1.2$)$ & $0.935^{\mathrm{b}}$ \\
\hline SSES & $2.6(-2.2$ to 7.3$)$ & $4.1(-0.8$ to 8.9$)$ & I.I (-1.9 to 4.1$)$ & $-1.6(-5.6$ to 2.5$)$ & $2.5(-2.0$ to 7.0$)$ & $0.267^{\mathrm{b}}$ \\
\hline GDS & $-1.0(-2.5$ to 0.4$)$ & $-1.6(-3.3$ to 0.1$)$ & $-0.3(-1.1$ to 0.5$)$ & $-0.2(-1.3$ to 0.8$)$ & $0.3(-1.0$ to 1.7$)$ & $0.604^{b}$ \\
\hline ZBI & $-2.0(-6.0$ to 2.1$)$ & $-3.2(-8.8$ to 2.4$)$ & $-3.9(-6.7$ to -1.2$)$ & $-4.5(-8.3$ to -0.8$)$ & $-2.2(-7.1$ to 2.7$)$ & $0.369^{c}$ \\
\hline
\end{tabular}

Notes: aBecause the interaction between time and treatment groups was insignificant, the adjusted between-group difference was based on the average effect at both 4 months and 12 months; ${ }^{b}$ controlled for age and sex of stroke patients, stroke type, household income, and the corresponding baseline outcome measures; ${ }^{c}$ controlled for age and sex of stroke patients and caregivers, stroke type, household income, baseline MBI, baseline MMSE, and baseline ZBI.

Abbreviations: Cl, confidence interval; GDS, Geriatric Depression Scale; MBI, Modified Barthel Index; MMSE, Mini-Mental Status Examination; SSES, State Self-Esteem Scale; ZBI, Zarit Burden Interview.

implying that the functional status could be further improved after 4 months up to 1 year. All other outcome measures did not show significant difference between the two follow-up times ( $P$-value ranged from 0.169 to 0.952$)$, implying that the cognitive status, self-esteem status, depression symptoms, and caregiver burden could be maintained from 4 months to 1 year.

\section{Institutionalization}

Of the 38 intervention participants who completed 1-year follow-up, six (15.8\%) were institutionalized. Among 23 control participants who were institutionalized (out of the 89 who completed 1-year follow-up), almost all of them were institutionalized immediately after inpatient discharge. Multiple logistic regression showed that the control group had a significantly higher risk of institutionalization at 1 year with an OR of 4.957 (95\% CI: 1.130-21.750). Other significant predictors to 1-year institutionalization were baseline functional status and sex of the patient. Higher institutionalization risk was associated with a baseline MBI score below 51 (OR $=7.695,95 \%$ CI: 2.303-25.710) and male patients ( $\mathrm{OR}=4.490,95 \%$ CI: $1.155-17.456$ ).

\section{Discussion}

This quasi-experimental study compared the rehabilitation and institutionalization outcomes among the stroke patients using short-term residential care for stroke rehabilitation and those using the usual GDH service. Assessment at 1 year showed that short-term residential care service promoted improvement in rehabilitation outcomes comparable with, if not better than, the usual GDH care. Furthermore, the study showed a significantly lower 1 -year institutionalization rate among those using short-term residential care for stroke rehabilitation.
The strength of this study was that this was a prospective study in evaluating self-financed short-term residential care for stroke rehabilitation with the usual care at GDH as a comparison group. The follow-up period was up to 1 year, such that the long-term difference in rehabilitation and institutionalization outcomes could be evaluated. In addition, caregiver's outcome was also included. The limitation of this study was the nonrandom assignment of groups, which may have resulted in selection bias. Nevertheless, the baseline differences were controlled by including the baseline characteristics as control variables in the data analyses. Meanwhile, potential observer bias may exist for the outcome measures because the assessors could not be blinded, as the first assessment was conducted on the date of admission at the service venue. The sample size depended on the number of stroke survivors choosing the new services, which limited the formal sample size calculation based on the treatment effect size. The small sample size in this study may limit the statistical power to detect smaller differences than medium effect size (Cohen's $d<0.5$ ), as well as lead to lower precisions in the estimations of CIs.

In terms of rehabilitation outcomes of the stroke patients and the outcome of the caregiver, our study found the new short-term residential care for stroke rehabilitation and the usual GDH care provided comparable improvements. This was consistent with a current review of transitional care after stroke hospitalization that there is no important difference among different types of transitional care. ${ }^{18}$ In fact, the intervention group showed greater point estimates of the improvements in MBI, SSES, and ZBI scores than the control group, despite the between-group differences not reaching statistical significance. A larger sample is required to increase the statistical power.

Without an appropriate rehabilitation program in a short-term residential care setting, the decision of 
institutionalization is often made at the time of inpatient discharge. Our study found that a quarter of the control participants entered residential care immediately after inpatient discharge. Similarly, about $26 \%$ of stroke survivors in Italy and $14 \%$ of stroke survivors in England, Wales, and Northern Ireland are institutionalized at discharge. ${ }^{6,29}$ Once institutionalization occurs, the stroke survivors seldom return to community living. ${ }^{6,29-31}$ It has been criticized that the decision of institutionalization at the time of discharge may be too early, depriving patients of maximizing the potential for functional recovery. ${ }^{29}$ Our findings suggest that it may not be the rehabilitation service itself but the availability of transitional residential care service that helps to delay the premature decision of institutionalization at inpatient discharge. At the same time, the stroke survivors could receive onsite rehabilitation with round-the-clock care when they were not ready to return home. Hence, the immediate need for institutionalization at inpatient discharge was reduced, and the decision could be made at the time of the end of the rehabilitation program. Because the patients had the hope of returning home after several months of rehabilitation, they would have motivation to proactively participate in the rehabilitation program. The provision of this type of service may be considered by other countries that wish to reduce institutionalization.

Our study also found that MBI score at the start of the rehabilitation program was a predictor of institutionalization. Although it is possible that the severity of initial stroke may be a driver of institutionalization, the capacity for stroke survivors to return to community living with the help of caregivers will also play a role. This speculation was consistent with a study conducted in England, Wales, and Northern Ireland that the most powerful predictor to institutionalization was the functional status at discharge, far greater than the predictive power of the initial stroke severity. ${ }^{29}$ Our study showed that the mode of delivery of rehabilitation provided additional institutionalization risk to the functional status at discharge. In other words, even for a stroke survivor with above average functional status, their risk of institutionalization within 1 year would be higher in the absence of transitional residential care.

For practical concern, starting up a residential care home solely for short-term stroke rehabilitation may not be costeffective. Instead, operating a short-term stroke rehabilitation unit within a current residential care home, just like the one we evaluated, should be considered. In this way, the kitchen, canteen, common room, and bathing facilities, etc, can be shared. Nevertheless, residential care homes have to be equipped with more rehabilitation equipment and personnel. In a previous study, we showed that users had high expectations of the quality of the services, including staff attitude, environment, meals, and personal care. ${ }^{19}$ Therefore, service providers should take into account other needs of the patients as well as their caregivers, in addition to the rehabilitation outcomes.

\section{Conclusion}

Our quasi-experimental study showed that a short-term residential care service tailored for stroke rehabilitation promoted improvement in rehabilitation outcomes comparable with, if not better than, the usual GDH care. Furthermore, a lower 1-year institutionalization rate was observed among those using short-term residential care. Transitional care in the form of short-term residential care tailored for stroke rehabilitation could be promoted to reduce institutionalization.

\section{Acknowledgments}

This study was funded by the Hong Kong Jockey Club Charities Trust under the CADENZA Fellowship Program. The authors would like to acknowledge the nongovernmental organization and the geriatric day hospital for participating in this study.

\section{Disclosure}

The authors report no conflicts of interest in this work.

\section{References}

1. Woo J, Ho SC, Yu LM, et al. Impact of chronic diseases on functional limitations in elderly Chinese aged 70 years and over: a cross-sectional and longitudinal survey. J Gerontol A Biol Sci Med Sci. 1998;53(2): M102-M106.

2. Kelly-Hayes M, Beiser A, Kase CS, et al. The influence of gender and age on disability following ischemic stroke: the Framingham study. J Stroke Cerebrovasc Dis. 2003;12(3):119-126.

3. Banaszak-Holl J, Fendrick AM, Foster NL, et al. Predicting nursing home admission: estimates from a 7-year follow-up of a nationally representative sample of older Americans. Alzheimer Dis Assoc Disord. 2004;18(2):83-89.

4. Brodaty H, Altendorf A, Withall A, Sachdev PS. Mortality and institutionalization in early survivors of stroke: the effects of cognition, vascular mild cognitive impairment, and vascular dementia. J Stroke Cerebrovasc Dis. 2010;19(6):485-493.

5. Chau PH, Woo J, Kwok T, et al. Usage of community services and domestic helpers predicted institutionalization of the elders having functional or cognitive impairments: a 12-month longitudinal study in Hong Kong. J Am Med Dir Assoc. 2012;13(2):169-175.

6. Panella M, Marchisio S, Brambilla R, et al. A cluster randomized trial to assess the effect of clinical pathways for patients with stroke: results of the clinical pathways for effective and appropriate care study. $B M C$ Med. 2012;10:71 doi: 10.1186/1741-7015-10-71.

7. Luengo-Fernandez R, Paul NL, Gray AM, et al. Population-based study of disability and institutionalization after transient ischemic attack and stroke: 10-year results of the Oxford Vascular Study. Stroke. 2013;44(10): 2854-2861. 
8. Petrea RE, Beiser AS, Seshadri S, et al. Gender differences in stroke incidence and poststroke disability in the Framingham Heart Study. Stroke. 2009;40(4):1032-1037.

9. Chan CKC, Chan DWC, Wong SKM. Evaluation of the functional independence for stroke survivors in the community. Asian J Gerontol Geriatr. 2009;4:24-29.

10. Chau PH, Kwok T, Woo J, et al. Disagreement in preference for residential care between family caregivers and elders is greater among cognitively impaired elders group than cognitively intact elders group. Int J Geriatr Psychiatry. 2010;25(1):46-54.

11. Rigby H, Gubitz G, Phillips S. A systematic review of caregiver burden following stroke. Int J Stroke. 2009;4(4):285-292.

12. Huang HC, Chung KC, Lai DC, Sung SF. The impact of timing and dose of rehabilitation delivery on functional recovery of stroke patients. J Chin Med Assoc. 2009;72(5):257-264.

13. Kwok T, Lo RS, Wong E, et al. Quality of life of stroke survivors: a 1-year follow-up study. Arch Phys Med Rehabil. 2006;87(9):1117-1182.

14. Good DC, Bettermann K, Reichwein RK. Stroke rehabilitation. Continuum (Minneap Minn). 2011;17(3):545-567.

15. Leeds L, Meara J, Hobson P. The impact of discharge to a care home on longer term stroke outcomes. Clin Rehabil. 2004;18:924-928.

16. Stolee P, Hillier LM, Webster F, et al. Stroke care in long-term care facilities in southwestern Ontario. Top Stroke Rehabil. 2006;13: 97-108.

17. Spruit-van Eijk M, Zuidema SU, Buijck BI, et al. Determinants of rehabilitation outcome in geriatric patients admitted to skilled nursing facilities after stroke: a Dutch multi-centre cohort study. Age Ageing. 2012;41:746-752.

18. Prvu Bettger J, Alexander KP, Dolor RJ, et al. Transitional care after hospitalization for acute stroke or myocardial infarction: a systematic review. Ann Intern Med. 2012;157(6):407-416.

19. Chau PH, Yeung F, Chan TW, Woo J. A quasi-experimental study on a new service option for short-term residential care of older stroke patients. Clin Interv Aging. 2013;8:1167-1175.
20. Shah S, Vanclay F, Cooper B. Improving the sensitivity of the Barthel Index for stroke rehabilitation. J Clin Epidemiol. 1989;42(8): 703-709.

21. Leung SOC, Chan CCH, Shah S. Development of a Chinese version of the Modified Barthel Index: validity and reliability. Clin Rehabil. 2007;21(10):912-922.

22. Chiu HFK, Lee HC, Chung WS, Kwong PK. Reliability and validity of the Cantonese version of the Mini-Mental State Examination: a preliminary study. J Hong Kong Coll Psychiatr. 1994;4(SP2):25-28.

23. Chiu HFK, Lee HCB, Wing YK, et al. Reliability, validity and structure of the Chinese Geriatric Depression Scale in a Hong Kong context: a preliminary report. Singapore Med J. 1994;35(5):477-480.

24. Heatherton TF, Polivy J. Development and validation of a scale for measuring self-esteem. J Pers Soc Psychol. 1991;60(6):895-910.

25. Chang AM. Psychosocial Nursing Intervention to Promote Self-Esteem and Functional Independence Following Stroke [dissertation]. Hong Kong: Chinese University of Hong Kong; 1999. Available from: Ann Arbor, MI: University Microfilms; AAI9945667.

26. Chau JPC, Thompson DR, Chang AM, Woo J. Psychometric properties of the Chinese version of State Self-Esteem Scale: an analysis of data from a cross-sectional survey of patients in the first four months after stroke. J Clin Nurs. 2012;21(21-22):3268-3275.

27. Zarit SH, Reever KE, Bach-Peterson J. Relatives of the impaired elderly: correlates of feelings of burden. Gerontologist. 1980;20(6): 649-655.

28. Chan TSF, Lam LCW, Chiu HFK. Validation of the Chinese version of the Zarit Burden Interview. Hong Kong J Psychiatry. 2005;15:9-13.

29. Portelli R, Lowe D, Irwin P, et al. Institutionalization after stroke. Clin Rehabil. 2005;19(1):97-108.

30. Sim TC, Lum CM, Sze FK, et al. Outcome after stroke rehabilitation in Hong Kong. Clin Rehabil. 1997;11(3):236-242.

31. Kramer AM, Steiner JF, Schlenker RE, et al. Outcomes and costs after hip fracture and stroke. A comparison of rehabilitation settings. JAMA. 1997;277(5):396-404. 


\section{Supplementary material}

Table SI Statistical models adopted for different outcome measures

\begin{tabular}{|c|c|c|}
\hline Outcomes & Model & Independent variables \\
\hline $\begin{array}{l}\text { Modified Barthel Index (MBI) } \\
\text { score }\end{array}$ & $\begin{array}{l}\text { Linear mixed-effects } \\
\text { model }\end{array}$ & $\begin{array}{l}\text { Treatment group, time of measurement, interaction between group and time, age } \\
\text { and sex of the stroke patients, stroke type, household income, baseline MBI score }\end{array}$ \\
\hline $\begin{array}{l}\text { Mini-Mental Status Examination } \\
\text { (MMSE) score }\end{array}$ & $\begin{array}{l}\text { Linear mixed-effects } \\
\text { model }\end{array}$ & $\begin{array}{l}\text { Treatment group, time of measurement, interaction between group and time, age } \\
\text { and sex of the stroke patients, stroke type, household income, baseline MMSE score }\end{array}$ \\
\hline $\begin{array}{l}\text { State Self-Esteem Scale (SSES) } \\
\text { score }\end{array}$ & $\begin{array}{l}\text { Linear mixed-effects } \\
\text { model }\end{array}$ & $\begin{array}{l}\text { Treatment group, time of measurement, interaction between group and time, age } \\
\text { and sex of the stroke patients, stroke type, household income, baseline SSES score }\end{array}$ \\
\hline $\begin{array}{l}\text { Geriatric Depression Scale (GDS) } \\
\text { score }\end{array}$ & $\begin{array}{l}\text { Linear mixed-effects } \\
\text { model }\end{array}$ & $\begin{array}{l}\text { Treatment group, time of measurement, interaction between group and time, age } \\
\text { and sex of the stroke patients, stroke type, household income, baseline GDS score }\end{array}$ \\
\hline $\begin{array}{l}\text { Zarit Burden Interview (ZBI) } \\
\text { score }\end{array}$ & $\begin{array}{l}\text { Linear mixed-effects } \\
\text { model }\end{array}$ & $\begin{array}{l}\text { Treatment group, time of measurement, interaction between group and time, age } \\
\text { and sex of the stroke patients, age and sex of the caregivers, stroke type, household } \\
\text { income, baseline MBI score, baseline MMSE score, baseline ZBI score }\end{array}$ \\
\hline Institutionalization rate at I year & $\begin{array}{l}\text { Multiple logistic } \\
\text { regression }\end{array}$ & $\begin{array}{l}\text { Treatment group, age and sex of the stroke patients, age and sex of the caregivers, } \\
\text { stroke type, household income, baseline functional status (high versus low), baseline } \\
\text { cognitive status (high versus low) }\end{array}$ \\
\hline
\end{tabular}

Clinical Interventions in Aging

\section{Publish your work in this journal}

Clinical Interventions in Aging is an international, peer-reviewed journal focusing on evidence-based reports on the value or lack thereof of treatments intended to prevent or delay the onset of maladaptive correlates of aging in human beings. This journal is indexed on PubMed Central, MedLine, the American Chemical Society's 'Chemical Abstracts Ser-

\section{Dovepress}

vice' (CAS), Scopus and the Elsevier Bibliographic databases. The manuscript management system is completely online and includes a very quick and fair peer-review system, which is all easy to use. Visit http://www.dovepress.com/testimonials.php to read real quotes from published authors.

Submit your manuscript here: http://www.dovepress.com/clinical-interventions-in-aging-journal 